\title{
DESLOCAMENTO DE CULTURA: UMA ANÁLISE DO FILME 1 FRANCO, 14 PESETAS E SUAS CONTRIBUIÇÕES PARA O ENSINO-APRENDIZAGEM DE LÍNGUA ESTRANGEIRA
}

\section{Cultural Dislocation: An Analysis Of The Movie 1 Franco, 14 Pesetas And Its}

Contributions To The Teaching And Learning Of Foreign Languages.

Désirée Luise KRIEGL, CELIN-UFPR ${ }^{1}$.

\begin{abstract}
RESUMO: Este artigo apresenta uma análise do filme espanhol 1 Franco, 14 Pesetas a partir da concepção Bakhtiniana de linguagem e de três categorias de deslocamento cultural - duplicação do outro, construções híbridas e exotopia - que representam os movimentos de aproximação de uma família espanhola com a cultura suíça. A análise tem como objetivo demonstrar como a utilização de filmes no ensino de língua estrangeira pode auxiliar em uma maior compreensão da cultura do outro. A partir do encontro com a outra cultura, o aluno é levado a repensar os próprios valores e evitar generalizações e estereótipos comuns no ensino-aprendizagem de línguas.
\end{abstract}

PALAVRAS-CHAVE: Deslocamento De Cultura; Filme; Ensino De Língua Estrangeira.

ABSTRACT: This article presents an analysis of the Spanish film 1 Franco, 14 Pesetas from the Bakhtinian conception of language and three cultural dislocation categories duplication of the other, hybrid constructions and exotopy - representing approximation movements of a Spanish family with the Swiss culture. The analysis aims to demonstrate how the use of films in teaching a foreign language can assist in a better understanding of the other culture. As a result of the encounter with another culture, the student is led to rethink his values and avoid generalizations and stereotypes common in language teaching and learning.

KEYWORDS: Cultural Dislocation; Film; Foreign Language Teaching.

\section{INTRODUÇÃO}

A utilização de filmes em salas de aulas é recorrente no ensino de língua estrangeira por ser este um material de grande aceitação pela maioria dos alunos. Por se tratarem de instrumentos audiovisuais, os filmes, ou trechos deles, possibilitam o

\footnotetext{
${ }^{1}$ Graduada em Letras (UFPR) e mestre em Educação (UFPR). desiluk@gmail.com.
} 
desenvolvimento de uma variedade de atividades que englobam as quatro habilidades de uma língua: compreensão oral, escrita, produção oral e leitura. Há diferentes objetivos a

serem trabalhados a partir de um vídeo e o que nos interessa aqui é explorar como eles podem contribuir para a expansão de conhecimento de mundo do aluno no tocante a sua cultura e as apresentadas pelo filme. Além disso, um filme como instrumento de ensino se diferencia do material mais comum em sala de aula, ou seja, do livro didático. Os filmes podem chamar a atenção do aluno de uma outra maneira para o tópico que se pretende estudar. Muitos livros didáticos produzidos para o ensino de língua estrangeira ainda demonstram uma escassez de ferramentas que funcionem para discussões mais abrangentes sobre cultura, isso porque boa parte deles ainda consideram a estrutura da língua como ensinamento primordial e acabam por priorizar regras gramaticais. Não é raro que um aluno, quando pensa em estudar uma nova língua, imagine que ela é construída por palavras e orações, ou seja, que ela é puramente estrutura e basta decorála e reproduzí-la. Isso porque muitos têm como base o livro didático que, por vezes, traz esse tipo de proposta. Porém, o papel do professor é mostrar ao aluno que o aprendizado de uma língua exige muitos outros conhecimentos.

Voloshinov $^{2}$ (2010) ao refletir sobre o aprendizado de um idioma considera que "a assimilação ideal de uma língua dá-se quando o sinal é completamente absorvido pelo signo e o reconhecimento pela compreensão". (BAKHTIN, 2010, p. 97 e 98). Para o autor, o principal dos métodos eficazes de ensino de idiomas é deixar o aprendiz familiarizado com o máximo possível de formas em que a língua pode acontecer em determinados contextos e situações concretas. A palavra utilizada fora de um contexto, apreendida por associação com o equivalente de outra língua, por exemplo, torna-se somente um sinal, ou seja, um signo que dificilmente será lembrado em uma situação em que poderia ser usado. Para o aluno que passa por um processo de compreensão da língua estrangeira, o fator de reconhecimento desse sinal assume uma força muito grande. Voloshinov (2010) destaca:

\footnotetext{
Em suma, um método eficaz e correto de ensino prático exige que a forma seja assimilada não no sistema abstrato da língua, isto é, como uma forma sempre idêntica a si mesma, mas na estrutura concreta da enunciação, como um signo flexível e variável. (BAKHTIN, 2010, p. 98)
}

\footnotetext{
${ }^{2}$ O autor do livro Marxismo e Filosofia da Linguagem (2010) é Valentin N. Voloshinov. Porém, a edição brasileira traz Mikhail Bakhtin como sendo autor da obra, por isso na referência aparecerá o nome de Bakhtin e no corpo será utilizado Voloshinov.
} 
É comum que pessoas que dominam muito bem uma língua sintam-se desamparadas em determinadas esferas da comunicação verbal. Bakhtin (2011) afirma

que isso acontece quando os sujeitos não dominam, na prática, as formas do gênero de determinadas esferas. Por exemplo, o autor diz ser muito comum um indivíduo que consegue se expressar perfeitamente numa esfera de comunicação cultural, ou falar a respeito de ciência, por exemplo, ficar calado ou intervir de maneira bastante desajeitada em uma conversa social. Bakhtin (2011) explica que isso acontece, mas:

\begin{abstract}
[...] não se trata de pobreza vocabular nem de estilo tomado de maneira abstrata; tudo se resume a uma inabilidade para dominar o repertório dos gêneros da conversa mundana, a uma falta de acervo suficiente de noções sobre todo um enunciado que ajudem a moldar de forma rápida e descontraída o seu discurso nas formas estilísticocomposicionais definidas, a uma inabilidade de tomar a palavra a tempo, de começar corretamente e terminar corretamente (nesses gêneros, a composição é muito simples). (Ibid., p. 285)
\end{abstract}

Aprender um novo idioma é muito mais complexo do que memorizar vocábulos e estruturas gramaticais. Para um sujeito ser capaz de se comunicar é necessário que este compreenda que cada contexto de uma dada cultura exige repertórios diferenciados. Voloshinov (2010) descarta o sistema abstrato de formas normativas como algo importante na prática da língua viva. Para ele, a consciência linguística do locutor e do receptor tem a ver com "a linguagem no sentido de conjunto de contextos possíveis de uso de cada forma particular" (BAKHTIN, 2010, p. 98). Os usuários proficientes da língua não vêm as palavras que utilizam como itens de um dicionário ou de uma gramática, mas sim como parte integrante das possíveis enunciações de diferentes locutores da comunidade da qual faz parte e do seu próprio repertório de práticas linguísticas. Voloshinov (2010) sintetiza esta ideia afirmando que:

\footnotetext{
Na realidade, não são palavras o que pronunciamos ou escutamos, mas verdades ou mentiras, coisas boas ou más, importantes ou triviais, agradáveis ou desagradáveis, etc. A palavra está sempre carregada de um conteúdo ou de um sentido ideológico ou vivencial. É assim que compreendemos as palavras e somente reagimos àquelas que despertam em nós ressonâncias ideológicas ou concernentes à vida. (BAKHTIN, 2010, p. 99)
}

O aprendizado de uma língua requer mais do que a decodificação de sinais, é necessário que os interlocutores sejam capazes de compreender e utilizar o idioma em diferentes contextos. O trabalho com filmes pode auxiliar nesse processo já que eles trazem uma variedade de enunciados em seu interior. As situações vividas pelos personagens exploram 
diferentes contextos que podem contribuir para a discussão sobre língua e, consequentemente, sobre cultura em sala de aula, já que entendemos que uma é indissociável à outra. As discussões

criadas a partir da exibição de um filme podem auxiliar na reflexão dos alunos sobre si mesmos em relação ao outro que foi observado. Através deste tipo de atividade proporciona-se aos indivíduos o encontro entre culturas e neste há sempre novas construções de sentido que irão modificar, de certa forma, as visões de mundo dos sujeitos envolvidos. Numa dimensão de sala de aula vale lembrar o que Tedeschi (2008) aponta sobre a discussão das diferenças culturais:

\footnotetext{
Numa perspectiva intercultural, não basta reconhecer a diferença, é preciso estabelecer uma relação, a inter-relação entre pessoas de culturas diferentes para justamente permitir um entendimento recíproco, de tal forma que essa relação implique um desafio à reelaboração de cada um. TEDESCHI, 2008; apud BRUZ, 2012, p.18)
}

A partir da análise de um filme é possível trabalhar com diversos aspectos dos enunciados e das imagens reproduzidas nele. Através da observação do comportamento dos personagens é possível detectar características culturais e identitárias, mesmo em se tratando de uma obra de ficção, que auxiliam em uma maior compreensão da cultura do outro. Considerando que o filme é uma forma de arte, cabe citar Cândido quando este afirma que a arte é social e:

[...] produz sobre os indivíduos um efeito prático, modificando a sua conduta e concepção do mundo, ou reforçando neles o sentimento dos valores sociais. Isto decorre da própria natureza da obra e independe do grau de consciência que possam ter a respeito os artistas e os receptores de arte. (CÂNDIDO, 2006, p. 29)

Para que o trabalho com o filme não seja somente mais uma atividade em sala de aula, é necessário que a escolha do mesmo envolva critérios com os quais se possa discutir os aspectos culturais. A opção pelo filme 1 Franco, 14 Pesetas do diretor Carlos Iglesias foi feita levando em consideração a análise possível dos aspectos sócio culturais desta obra e dos deslocamentos de cultura nela presentes.

Para tanto, utilizaremos as categorias que Janzen (2005) propõe embasado na teoria da linguagem do Círculo de Bakhtin: duplicação do outro, construções híbridas e exotopia. Através delas podemos descrever os movimentos que aproximam os personagens do filme da cultura do outro. Janzen afirma: "Entendemos que a formação da visão de mundo, dá-se no movimento duplo de aproximação/distanciamento do outro e na natureza dialógica da linguagem" (JANZEN, 2005, p.50). Através de exercícios que proporcionem esta aproximação/distanciamento entre os elementos culturais do outro, trazido pelo filme, e o aluno é possível que este último compreenda melhor os 
valores das culturas apresentadas e os seus próprios. Este movimento irá possibilitar um acabamento da cultura do aluno, ou seja, através do olhar sobre o outro o indivíduo tem um novo entendimento da sua própria cultura.

\section{ENREDO DO FILME}

1 Franco, 14 Pesetas é baseado em fatos reais e conta a história de dois amigos, Martin e Marcos, que migram de Madri na Espanha para a Suíça na década de 60. O título do filme tem duplo sentido já que faz alusão ao câmbio de moedas da época, o franco suíço e a peseta espanhola, como também ao ditador Francisco Franco que governou a Espanha de 1939 a 1975. Nesta época, segundo o enredo do filme, o país passa por uma crise e Martin acaba perdendo seu emprego. Para agravar a situação, neste mesmo momento a esposa de Martin, Pilar, dá entrada para a compra de um apartamento sem o conhecimento do marido e sem saber que este não terá condições de arcar com a dívida.

Vendo-se sem recursos para manter a sua família, Martin e seu amigo Marcos deixam as suas famílias na Espanha e vão para um lugar novo e desconhecido, de progresso e liberdade. Ali eles descobrem uma realidade muito diferente daquela a que estão acostumados e à qual deverão se adaptar. Os dois amigos começam a trabalhar como mecânicos em uma pequena vila na cidade industrial de Uzwil, Suíça. Com a distância dos familiares e a liberdade que tinham, eles iniciam um relacionamento com duas mulheres do local. Martin com Hanna, a dona do hotel onde estavam hospedados, e Marcos com uma funcionária do lugar.

Com a chegada surpresa à Suíça de Pilar e Pablo, filho de Martin, o romance do protagonista e do amigo é interrompido. Logo depois chega também Carmen, noiva de Marcos com vistas a se instalar no novo local. Pablo começa a frequentar a escola onde convive com a nova cultura e a língua do local. Depois de 5 anos,a família já está muito bem adaptada ao país porém, quando o pai de Martin morre, Martin e Pilar decidem que é hora de voltar à Espanha, pois já haviam conseguido o que tinham ido buscar na Suíça: melhores condições de vida e dinheiro para comprar o tão sonhado apartamento para a família.

\section{DESLOCAMENTO DE CULTURA}

Para a análise dos deslocamentos de cultura presentes nesta obra serão utilizadas as categorias que Janzen (2005) propõe embasado na teoria da linguagem do Círculo de 
Bakhtin: duplicação do outro, construções híbridas e exotopia. Storck e Janzen (2013) descrevem as categorias mencionadas anteriormente e que serão utilizadas para a análise do filme 1 Franco 14 Pesetas. São elas:

Duplicação do outro: nesta categoria o outro é percebido pela projeção que o indivíduo faz da própria cultura, e que geralmente está carregada de estereótipos. Quando olhamos para o outro com os parâmetros e valores da nossa própria cultura é comum que haja estranhamento. As diferenças e contrastes culturais podem ser vistos com estranheza pelo indivíduo que está em contato com a cultura alvo. O que não estiver de acordo com aquilo a que se está acostumado pode ser anormal aos olhos de quem vê e será comparado com base numa escala única de valores, os da própria cultura. Por isso, considera-se que a duplicação do outro "é uma ideia homogeneizante, na qual há uma generalização por parte de um grupo, que limita os valores da cultura alheia" (STORCK, 2011, p. 48). A tendência, neste caso, é que o indivíduo formule uma visão distorcida sobre a cultura alvo, avaliando o outro como parte de um grupo homogêneo. Para explicar como se dá esta visão homogeneizante Janzen (2005) apresenta o termo etnocentrismo que a resume muito bem:

[...] uma tendência a considerar as categorias, normas e valores da própria sociedade ou cultura $[\ldots]$ como parâmetros aplicáveis às demais. Uma perspectiva etnocêntrica pode gerar uma visão distorcida e parcial ou mesmo assimétrica da cultura-alvo, podendo desencadear um movimento de rejeição a esta. (JANZEN, 2005, p. 35)

Construção híbrida: O hibridismo é caracterizado pela presença de dois eixos axiológicos em um enunciado produzido por um único falante. Duas vozes podem ser percebidas na construção de um mesmo conjunto sintático. Neste sentido, Bakhtin define o conceito:

\footnotetext{
Denominamos construção híbrida o enunciado que, segundo índices gramaticais (sintáticos) e composicionais, pertence a um único falante, mas onde, na realidade, estão confundidos dois enunciados, dois modos de falar, dois estilos, duas "linguagens", duas perspectivas semânticas e axiológicas. Repetimos que entre esses enunciados, estilos, linguagens, perspectivas, não há nenhuma fronteira formal, composicional e sintática: a divisão de vozes e das linguagens ocorre nos limites de um único conjunto sintático, freqüentemente nos limites de uma proposição simples, freqüentemente também um mesmo discurso pertence também simultaneamente às duas línguas, às duas perspectivas que se cruzam numa construção híbrida, e, por conseguinte, tem dois sentidos divergentes, dois tons. (BAKHTIN, 1988, apud JANZEN, 2005, p. 59)
} 
A construção híbrida é a fronteira entre a cultura do indivíduo e a cultura do outro. Os enunciados produzidos nesta fronteira, a partir do conceito de enunciado dialógico de Bakhtin, nunca são somente um enunciado. Este é formado por vozes diversas, a partir de eixos valorativos diferentes que irão formar um novo enunciado. $\mathrm{O}$ encontro desses eixos axiológicos distintos formará o que Bhabha (2013) chama de terceiro espaço e que será diferente tanto de um quanto do outro. Bhabha (2013) afirma que "nenhuma cultura é unitária em si mesma, nem simplesmente dualista na relação do Eu com o Outro" (Ibid., p. 71). Todo o encontro entre culturas gera mudanças que poderão ser notadas tanto em uma como na outra e por isso as culturas não são estáticas.

Exotopia: esse conceito é desenvolvido por Bakhtin quando o autor reflete sobre a criação literária e é utilizado como uma das categorias para a análise dos deslocamentos de cultura. Janzen $(2005$, p. 61) diz que a "exotopia, 'o estar do lado de fora', o não coincidir com o outro, constitui uma questão fundamental na reflexão que envolve a alteridade intercultural, 'o estar do lado de fora cultural'". Assim sendo, é mais fácil compreender o outro quando não se é parte dele. A distância, não necessariamente a física, é essencial para o sujeito enxergar aquilo que nem mesmo o indivíduo que está inserido em sua cultura consegue ver.

Uma das características da exotopia é o excedente de visão e, para Bakhtin: “o excedente de minha visão, com relação ao outro, instaura uma esfera particular da minha atividade, isto é, um conjunto de atos internos ou externos que só eu posso préformar a respeito desse outro e que o completam justamente onde ele não pode completar-se" (BAKHTIN, 1997, apud JANZEN, 2005, p. 61). Isto é, aquilo que não consigo ver de mim mesmo pode ser observado pelo outro através do excedente de visão e este outro completa aquilo que eu não sou capaz de preencher. Para tanto, a empatia é necessária já que neste processo o sujeito se coloca no lugar do outro e consegue compreendê-lo melhor. O processo de empatia também é característica da exotopia, pois só é possível se colocar no lugar do outro não coincidindo com ele. A empatia também é importante, segundo Bakhtin, para que seja possível ver mundo a partir do olhar do outro e não através do seu próprio eixo axiológico:

Bakhtin postula neste processo dialógico a efetivação da empatia: 'ver o mundo através dos valores do outro', percebendo coisas que só são acessíveis a um dos interlocutores, para depois retornar (através da contemplação) à posição inicial, que possibilita elaborar o seu acabamento e o do outro. Quando Bakhtin se refere a esta perspectiva exotópica na vida, ressalta que a riqueza da exotopia não está na duplicação do semelhante, porém no fato de que este outro vive (e continua vivendo) numa categoria de valores diferentes. (JANZEN, 2005, p.61) 
Para que seja possível fazer o que chamamos de "acabamento" da cultura do outro é necessário compreender mais abrangentemente este outro e não necessariamente aceitá-lo. Deve-se saber que o outro vive em um diferente eixo axiológico de valores

distintos. O processo de acabamento se dá quando consegue-se ver o outro através do eixo axiológico do outro e não do seu próprio formulando assim uma nova compreensão deste outro.

As categorias aqui expostas (duplicação do outro, construções híbridas e exotopia) embasarão a análise das cenas do filme 1 Franco, 14 Pesetas que serão expostas neste artigo e que podem vir a ser trabalhadas em sala de aula em forma de atividades de cunho intercultural.

\section{ANÁLISE DE 1 FRANCO, 14 PESETAS}

O início do filme 1 Franco, 14 Pesetas é marcado por diversas cenas nas quais os amigos Martin e Marcos duplicam o outro. O estilo de vida que levavam na Espanha não se compara ao da Suíça e a cultura da qual faziam parte nada se assemelha àquela do país onde foram buscar trabalho. Em uma das primeiras cenas deles na Suíça é possível notar o estramento diante da cultura do outro. Martin e Marcos estão em um trem com destino à cidade de Uzwil, e nele sentem o primeiro choque entre culturas. Os amigos comem um sanduíche e quando terminam o lanche, sem notar aquela ação como sendo uma ofensa ou algo fora dos padrões, jogam o papel que envolvia o alimento no chão. Uma senhora já de idade está sentada ao lado e com ar de reprovação levanta, se curva para pegar o papel e o joga no lixo. A senhora muito provavelmente reconhece que aqueles homens são estrangeiros e, numa tentativa de mostrar qual era o correto segundo o seu eixo axiológico de valor, realiza aquilo que ela acredita que deveria ter sido feito. Os amigos se olham e estranham aquele movimento, perguntando-se o porquê daquilo. No filme os suíços demostram nesta situação que se preocupam muito com a limpeza e que jogar lixo no chão seria considerado extrema falta de educação.

Ainda no trem, eles observam um casal de namorados que se beija em público. Surpresos com a cena, eles continuam olhando e comentam como se aquilo fosse algo não permitido. De fato, a liberdade suíça era bem diferente daquela que conheciam em Madrid. Com a ditadura franquista regendo a Espanha dos anos 60 não era permitido aos casais demonstrações de carinho em público. 
Já na cidade de destino, Martin e Marcos se espantam com a calmaria do lugar. Não há ninguém nas ruas por onde passam e esta não era uma cena comum para os espanhóis. Finalmente encontram um senhor que lhes dá informações em alemão, língua de que não entendem uma palavra até aquele momento. Pelo que conseguem entender,

acreditam que está acontecendo uma feira na cidade e que os moradores haviam parado o trabalho para participar do evento. Acham o fato um absurdo já que na Espanha isso seria inviável. Aqui há novamente uma demonstração de duplicação do outro. Mesmo que tenham entendido errado por desconhecer a língua local, Martin e Marcos não acham correto que o trabalhador pare o seu serviço devido a uma feira. Isso porque estão projetando o outro a partir do próprio eixo axiológico, único que conhecem até então. Neste momento, o senhor, entendendo que eram dois trabalhadores estrangeiros, situação comum na cidade, guia-os até o hotel de Hanna onde ficam hospedados até a chegada da esposa de Martin.

Quando chegam no hotel, Hanna vê a dificuldade que os dois enfrentam com a língua e fala italiano com eles, língua mais próxima do espanhol. Martin e Marcos ficam muito entusiasmados com tudo, já que o luxo que iriam ter em Uzwil não teriam em Madrid. No hotel os amigos foram agraciados com um quarto para os dois no qual contavam com camas confortáveis, um banheiro com água quente e café da manhã incluso na despesa de estadia. Neste momento ainda é inevitável a duplicação do outro e da outra cultura. Os amigos projetam a outra cultura sempre a partir da sua própria. Mesmo contentes com todas as novidades, é complicado para Martin e Marcos lidar com as diferenças culturais. Habituados a utilizar jornal no banheiro, ficam muito impressionados quando notam que lá eles usam papel higiênico de boa qualidade e que tem água quente nas torneiras. A Suíça nesta época é um país de progresso e de liberdade se comparado à Espanha. É necessário algum tempo para que os dois amigos se acostumem com a nova vida. O contraste cultural é intenso, no entanto eles não rejeitam esta nova cultura, o que facilita o processo de compreensão do outro.

No filme de Carlos Iglesias, há alguns momentos nos quais é possível identificar construções híbridas. Um ano depois, já bem adaptados à nova cultura, Martin e Marcos já falam um pouco de alemão, uma das línguas locais, e compreendem melhor os valores culturais do local onde estão. Os estereótipos comuns no início da jornada na Suíça já não têm mais espaço, pois a compreensão do outro já é desenhada a partir de dois eixos axiológicos. Aqui Martin e Marcos já distinguem esses dois eixos 
valorativos, o espanhol e o suíço, e transitam neste entre-lugar. No aniversário de Martin, por exemplo, Marcos começa um affair com Erika, funcionária de Hanna no Hotel. Mesmo estranhando o fato de uma mulher lhe pedir para dançar, o rapaz aceita o pedido. Esta relação pode ser vista como uma construção híbrida, pois Marcos sabe que

em sua cultura ele não tem a mesma liberdade e não poderia estar com outra mulher, já que está noivo de Carmen na Espanha. Mesmo assim, o engenheiro aproveita e usufrui da liberdade que o país lhe permite. Martin é um pouco mais resistente, afinal é casado e tem um filho que havia deixado no seu país de origem. No entanto, ele acaba cedendo aos encantos de Hanna, a bela suíça loira e de olhos azuis, características não comuns para uma mulher na Espanha, que se apaixona por ele.

Demonstrações de carinho em público eram naturais aos olhos dos suíços naquela época, enquanto que para os espanhóis que viviam sobre o regime ditatorial de Francisco Franco, esse tipo de cena não era permitido. Além disso, na Espanha dos anos 60 as mulheres eram proibidas de fazer muitas coisas, como trabalhar e ter direito a voto, por exemplo. Em 1 Franco, 14 Pesetas, Hanna - uma mulher suíça - é dona do seu próprio negócio e tem autonomia em suas escolhas.

Quando Martin começa a gozar da liberdade em Uzwil, no passado moldada nos padrões da cultura de origem, sua esposa Pilar e seu filho Pablo chegam de surpresa na cidade. Martin, que já está bem inserido na cultura local, traduz tudo o que os nativos dizem a sua esposa. Pilar desconfia do relacionamento do marido com a dona do hotel e aproveita da fragilidade dele para pedir que se mudem para um outro lugar que não fosse o hotel. Então, Martin e a família vão morar em um apartamento com o qual Pilar sonha desde o casamento.

No novo apartamento, uma duplicação ocorre do lado oposto. Agora é a vez dos suíços estereotiparem a cultura dos espanhóis. Uma vizinha fica espantada e alerta a proprietária do imóvel quanto aos novos moradores, Martin e a família, pois em sua visão os espanhóis não cuidam bem de suas residências, ainda mais tendo filhos, sinônimo de bagunça. No entanto, esta visão muda no decorrer dos cinco anos nos quais a família permanece por lá. Os vizinhos acabam por gostar da família e têm uma boa relação com eles.

Mesmo sem a autorização de Martin, que não aceitava que a sua mulher tivesse um emprego, Pilar começa a trabalhar em uma lavanderia. Aqui, a esposa de Martin passa por cima das regras espanholas e vive no sistema de valores suíço. Ela não 
abandona a sua raiz cultural mas, vendo a necessidade de ajudar seu marido, ela decide transitar pelo eixo axiológico suiço.

Sem ter onde ficar, Pablo começa a frequentar uma escola local. O primeiro dia de aula é muito chocante para o menino. Novo país, novas regras, nova língua, novos

amigos; tudo fazia parte de uma cultura estranha com a qual ele nunca havia tido contato. Uma das regras da escola era tirar os sapatos na entrada e utilizar chinelos. Como era o primeiro dia de Pablo, este não portava todos os materiais necessários. $\mathrm{O}$ pai pergunta à professora em alemão se Pablo pode ficar com os sapatos pelo menos em seu primeiro dia, pois descalço correria o risco de ficar com dor de garganta. Apesar do enunciado inicialmente produzido com base em suas referências culturais, Martin reproduz ao menino o enunciado da professora, que dizia ser saudável andar descalço. Ao aceitar o que foi dito pela professora e repassar isto ao filho Martin caminha por diferentes eixos valorativos. Isto não acontece quando o pai pergunta à professora quanto é a mensalidade da escola tendo como referência as escolas do seu país. A duplicação da sua própria cultura ainda está presente e faz com que Martin imagine que seria caro manter o filho em uma escola com aquele padrão de excelência, no entanto, o ensino em Uzwil é oferecido gratuitamente.

Cinco anos se passam, e Pablo está tão habituado ao país que já se sente como um nativo. Contudo, diante de algumas situações as referências de Pablo continuam sendo as da cultura espanhola mesmo que ele compreenda os valores culturais suíços. Durante uma aula sobre reprodução humana na escola, Pablo explica que compreende que os bebês suíços venham de suas mães, porém explica com a maior naturalidade que os bebês espanhóis vêm de Paris carregados por cegonhas. Mesmo vivendo em um país no qual a educação sexual não é tabu, Pablo convive com os dois eixos valorativos, aquele da cultura de seu país de origem e o suíço. Ao chegar em casa e contar o acontecido, Pablo causa o espanto de sua mãe Pilar. Esta, que ainda transita pela categoria da duplicação, não aceita completamente a outra cultura e a coloca sempre como inferior a sua. Pilar acha errado o que as crianças aprendem na escola e considera que essa é a explicação para o comportamento libertário dos adultos. A visão de Pilar sobre a cultura do outro é estereotipada. Apesar do tempo que a espanhola mora no país, ela ainda julga o outro a partir dos seus valores. Em todo decorrer do filme há uma tendência homogeinizante por parte de Pilar sobre a cultura alheia como se todos fossem representados por um só perfil. 
Pilar é, sem dúvida, o personagem que se mantem mais fixamente na categoria de duplicação do outro. Na cena em que ela vai ao mercado com o filho Pablo, Pilar insiste em pedir carne de fígado para o açougueiro utilizando o espanhol. $\mathrm{O}$ atendente suíço não compreende a língua, mas ainda sim se esforça para atender o pedido da

cliente. Pablo vendo a dificuldade de comunicação dos dois, fala em alemão com o funcionário que, assim, compreende o que Pilar deseja. O menino, nesta situação, já consegue se colocar do outro lado, analisar o outro a partir do excedente de visão, pois insinua à mãe que ela já deveria saber como pedir fígado no mercado já que ela está no país há cinco anos e sempre compra carne. Pilar, ainda resistente, diz que o açougueiro é quem deveria compreender a sua língua.

$\mathrm{Na}$ categoria de exotopia ainda temos alguns outros exemplos em cenas finais da obra. Quando Martin decide voltar à Espanha, o protagonista já consegue compreender profundamente a cultura suíça analisando o outro a partir dos valores do outro até ao ponto de sentir falta de muitos elementos culturais de lá e criticar outros da Espanha. Sua visão mais abrangente sobre a cultura do outro ajuda ele a descrever as diferenças do lugar com a Espanha em uma cena em que conversa com Pablo. O menino, que já se considera um nativo, não quer voltar para a Espanha, pois os seus laços mais fortes foram construídos na Suíça, é lá que ele tem seus amigos, são as paisagens de lá que o encantam e é a escola de lá com a qual está acostumado. Esse sentimento de pertencimento à cultura estrangeira fica claro no momento do filme em que Pablo se despede dos amigos prometendo um dia voltar. Os meninos, acostumados com estrangeiros indo e vindo ao seu país, falam que isso não irá acontecer, pois os estrangeiros nunca voltam. Como reação, Pablo diz não ser estrangeiro, somente os seus pais o são. O fato de ter passado boa parte da sua infância na Suíça fez com que Pablo sentisse como se os valores deste país fossem os seus e a cultura espanhola fosse a outra. Mesmo que tenha passado por todas as fases de deslocamento cultural na Suíça, Pablo irá reviver esse processo quando é obrigado a voltar para Madrid.

De volta à Espanha, Pablo se sente um estrangeiro em seu próprio país. O menino estranha a paisagem da Espanha e não gosta do que vê. A comparação que faz é com a vida que levava na Suíça. Para Pablo, o apartamento para o qual se mudam na Espanha não tem a vista agradável com a qual estava acostumado, aliás não tem nenhuma vista, fica de frente para outros vizinhos do mesmo prédio. Tudo parece de menor valor para Pablo, mas o menino deverá se acostumar à nova vida, pois a família 
está decidida a ficar. Uma última cena marca o excedente de visão por parte da família de Martin e acontece no apartamento em Madrid. Dois encanadores fazem consertos na cozinha e, em conversa, a família comenta que esteve morando na Suíça por cinco anos e que tinham voltado há pouco tempo. Os encandores comentam que a família deve ter

sofrido muito preconceito na Suíça, pois o povo de lá não é tão receptivo quanto os espanhóis. Em defesa aos suíços, a família nega ter sofrido e Pablo manifesta a sua preferência pela Suíça. Pilar ainda friza que os espanhóis são receptivos somente com os alemães cheios de dinheiro e com as belas suíças. Esta é uma das únicas vezes que ela demonstra empatia com a cultura do país em que morou parecendo compreender melhor os valores da sua própria.

Marcos e a esposa continuam na Suíça e recebem uma carta de Martin que fala da sua situação na Espanha. O protagonista fala da sua dificuldade em encontrar um emprego e da falta que sente de certos aspectos suíços. Carmen resume este sentimento afirmando ser curioso o fato de que quando estão na Suíça sentem falta da Espanha e quando estão na Espanha é a Suíça que faz falta, fato que demonstra que os dois eixos valorativos estão internalizados e tanto a sua cultura como a do outro já fazem parte de suas vidas.

\section{CONSIDERAÇÕES FINAIS}

Mais uma vez, a afirmação de Bhabha em $O$ local da cultura se mostra pertinente: "nenhuma cultura é unitária em si mesma, nem simplesmente dualista na relação do Eu com o Outro" (Bhabha, 2013, p. 71) e sintetiza que pertencemos, acima de tudo, a uma cultura da humanidade. O movimento de encontro com a outra cultura não necessariamente precisa trazer o gosto por ela, mas o olhar para o outro através dos valores deste transforma a visão de mundo do indivíduo. A análise do filme revela que este é um instrumento precioso para o trabalho sobre cultura no ensino-aprendizagem de língua estrangeira. O exemplo é de um filme espanhol que representa duas culturas contrastantes, a da Espanha e a da Suíça, no entanto, há muitos outros exemplos de filmes e recursos audiovisuais com os quais é possível realizar o mesmo trabalho.

Em sala de aula, o ensino da língua estrangeira deve abranger mais do que tão somente a sua estrutura. Para além da gramática, o aprendizado de uma segunda língua requer que o aprendiz mergulhe nas culturas que aquele idioma traz junto com ele. Para tanto, a metodologia de análise utilizada para descrever as cenas de 1 Franco, 14 
Pesetas neste artigo podem ser utilizadas para guiar uma discussão em sala de aula sobre diferentes culturas. Por meio deste filme, por exemplo, é possível mostrar ao aluno como é fácil reproduzirmos estereótipos de outras culturas quando não a conhecemos de fato, ou então quando a observamos a partir dos valores que julgamos

corretos. Explicar ao aprendiz que a duplicação do outro é comum quando analisamos as outras culturas a partir do nosso próprio eixo valorativo ajuda o aluno a se perceber melhor e a tentar compreender a visão de mundo do outro. O reconhecimento da existência de diferentes valores facilita as construções híbridas e a sua percepção pelos alunos. Mostrar ao aprendiz que o encontro entre culturas tem o potencial de transformá-las, assim como aconteceu com os personagens do filme aqui analisado, é relevante para que o aluno perceba que é por meio deste contato entre culturas que a melhor compreensão da língua irá acontecer, já que cultura e língua são inseparáveis.

Quando lançamos o olhar ao outro, o processo de empatia é essencial e deveria ser uma premissa em sala de aula. Ao se colocar no lugar do outro, o aluno é levado a compreender o outro através dos valores do outro. O interesse pela exotopia, o não coincidir com o outro, está justamente em não duplicar o outro, mais entender que ele vive em um eixo valorativo diferente e isso continuará desta forma. O importante no aprendizado de uma língua estrangeira é que o aluno perceba as diferentes categorias valorativas das outras culturas e consiga separá-las das suas. Neste sentido, o trabalho com filmes pode facilitar essa percepção por parte dos aprendizes e as categorias de análise neste artigo demonstradas auxiliariam nesse processo. A partir do enredo, dos personagens e de suas ações, a reflexão sobre língua e cultura é facilitada já que os filmes são instrumentos audiovisuais e que geralmente agradam os alunos quando utilizados por professores em sala de aula.

\section{REFERÊNCIAS BIBLIOGRÁFICAS}

BAKHTIN, M. Estética da Criação Verbal. $6^{a}$ ed. São Paulo: Martins Fontes, 2011. . Marxismo e Filosofia da Linguagem. 14ª ed. São Paulo: Hucitec, 2010.

BHABHA, H. O Local da Cultura. Belo Horizonte: UFMG, 2013.

BRUZ, I. M. Análise de livros didáticos de língua inglesa sob o viés da interculturalidade. Dissertação (Mestrado em Educação). UFPR, Curitiba, 2012.

CÂNDIDO. A. Literatura e sociedade. Rio de Janeiro: Ouro Azul, 2006.

JANZEN, H. O Ateneu e Jakob Von Gunten: um diálogo intercultural possível. 171f. Tese (Doutorado em Língua e Literatura Alemã), Faculdade de Filosofia, Letras e Ciências Humanas da Universidade de São Paulo. São Paulo, 2005. 
JANZEN, H. E.; STORK. D. Autoria, Intervenção e Deslocamento Cultural: uma análise Intercultural. Educação \& Realidade, Porto Alegre, v. 38, n. 1, p. 319-337, jan./mar. 2013. Disponível em: 〈http://www.ufrgs.br/edu_realidade>

STORCK, D. F. Autoria, autonomia e algumas intervenções: uma análise intercultural do livro didático "Keep in mind" a partir das concepções bakhtinianas de linguagem. Dissertação (Mestrado em Educação), Universidade Federal do Paraná. Curitiba, 2011. 